Geraldina da Costa Ribeiro Matos (iD) http://orcid.org/0000-0002-0833-7535

Jandira Maciel da Silvab

(iD) https://orcid.org/0000-0002-9990-9323

Andréa Maria Silveirab

(D) http://orcid.org/0000-0002-1180-3875

a Secretaria Municipal de Saúde de Belo Horizonte. Belo Horizonte, MG, Brasil.

${ }^{\mathrm{b}}$ Universidade Federal de Minas Gerais (UFMG), Faculdade de Medicina, Departamento de Medicina Preventiva e Social. Belo Horizonte, MG, Brasil.

Contato:

Andréa Maria Silveira

E-mail:

silveira@medicina.ufmg.br

As autoras declaram que o trabalho não foi subvencionado e que não há conflitos de interesses.

As autoras informam que o trabalho não foi apresentado em evento científico e que foi baseado na dissertação Trabalhoe saúde: a perspectiva dos agentes de combate a endemias de Belo Horizonte, de autoria de Geraldina da Costa Ribeiro Matos, defendida em 2017 na Faculdade de Medicina da Universidade Federal de Minas Gerais, Belo Horizonte, MG, Brasil.

\section{Trabalho e saúde: a perspectiva dos agentes de combate a endemias do município de Belo Horizonte, MG}

\author{
Work and health: the perspective of the endemic diseases control \\ agents of Belo Horizonte, Minas Gerais, Brazil
}

\section{Resumo}

Introdução: a incidência de zoonoses é alta no Brasil. O agente de combate a endemias (ACE) é um dos principais atores no enfrentamento destas doenças. Objetivo: Identificar e compreender a percepção do ACE sobre o seu trabalho, com enfoque na relação entre trabalho e saúde. Métodos: estudo transversal, qualitativo, sob o aporte teórico das clínicas do trabalho. Utilizou-se pesquisa bibliográfica e documental, grupo focal e análise de conteúdo. O trabalho foi realizado em Belo Horizonte (MG), no período de março de 2016 a abril de 2017. Resultados: o serviço de zoonoses é percebido pelos profissionais como não integrado à área da saúde, e essa seria uma das causas da precariedade das condições de trabalho, do sentimento de invisibilidade e da marginalização simbólica e concreta vivenciada. Os trabalhadores reconhecem os riscos à saúde a que estão expostos, com destaque para a violência, falta de equipamentos de segurança adequados e riscos psicossociais. Conclusão: a pesquisa revela a invisibilidade e o sofrimento vivenciado pelos ACE e a necessidade de mudanças na organização do trabalho visando à proteção da saúde desses trabalhadores.

Palavras-chave: doenças endêmicas; condições de trabalho; saúde do trabalhador.

\begin{abstract}
Introduction: there is a high incidence of zoonoses in Brazil. Endemic diseases control agents (ECA) are one of the main actors in the fight against these diseases. Objective: to identify and understand the ECA's perception of their work, focusing on work-health relations. Methods: qualitative cross-sectional study based on the Clinic of Activity theory. We used bibliographical and documentary research as well as focal groups and content analysis. This study was conducted in Belo Horizonte (Minas Gerais) from March 2016 to April 2017. Results: ECA do not perceive the activities of zoonoses' control as integrated with the health service, and consider this as one of the causes of the precariousness in their work conditions, of their feeling of being invisible, and of the symbolic and concrete marginalization they experience. The workers recognize the health hazards they are exposed to, especially regarding violence, lack of suitable protection equipment and psychosocial risks. Conclusion: ECA experienced suffering and invisibility. Changes in work organization are required to protect workers' health.
\end{abstract}

Keywords: endemic diseases; work conditions; occupational health. 


\section{Introdução}

Elemento estruturante da sociedade e central na vida do homem, o trabalho é um dos principais instrumentos de relacionamento entre o sujeito e seu meio social, um processo criativo e construtivo por meio do qual o sujeito se desenvolve e se reafirma ${ }^{1}$.

No entanto, o trabalho não está isento de contradições. Enriquez ${ }^{2}$ observa que a produção, principal fonte de sustentação da sociedade capitalista, tem sufocado as possibilidades de criação e que a alienação nunca foi tão intensa. O autor afirma que o "culto à performance e à urgência está reinando, os coletivos estão se rompendo, o estresse profissional e até mesmo o assédio se tornam uma realidade cotidiana” (p. 172).

A Organização Internacional do Trabalho (OIT) ${ }^{3}$ apresenta um cenário preocupante no que se refere à relação entre trabalho e saúde. Segundo relatório por ela publicado em 2013, estima-se que cerca de 2,34 milhões de pessoas morrem todos os anos em decorrência de acidentes e doenças relacionadas com o trabalho. O documento destaca ainda que, embora tenham diminuído em virtude de uma melhor regulamentação e dos avanços tecnológicos, alguns riscos tradicionais ainda estão presentes nos contextos laborais e convivem com novos riscos (dentre os quais se destacam os psicossociais), suscitados pelas novas tecnologias e formas de organização voltadas para o aumento da produtividade.

A exigência do cumprimento de metas, resultados e indicadores dissociada da oferta de condições de trabalho adequadas é cada vez mais comum nas organizações privadas e públicas, inclusive no Sistema Único de Saúde (SUS). Nada mais atual do que a observação de Mehry ${ }^{4}$, que observa que um dos pontos mais problemáticos no SUS é o modo como são estruturados e gerenciados os processos de trabalho nos diferentes estabelecimentos que ofertam serviços de saúde, como por exemplo no setor de zoonoses.

A incidência de zoonoses permanece alta em quase todos os países em desenvolvimento, inclusive no Brasil. $\mathrm{O}$ agente de combate às endemias (ACE) é um dos principais atores no enfrentamento dessas doenças. Esse profissional exerce ações de vigilância, prevenção, controle de doenças e promoção da saúde, tendo como cenário de intervenção o ambiente em que as pessoas residem. Ele está sujeito a todas as questões do cotidiano das comunidades, como a violência e situações de vulnerabilidade, ficando exposto a muitos riscos, inclusive psicossociais ${ }^{5}$.

Oliveira $^{6}$ destaca que a organização das ações de controle de endemias apresenta forte tendência à gestão verticalizada, com estabelecimento de metas objetivas e quantificáveis. Além disso, atualmente as novas doenças associadas ao Aedes aegypti são um dos maiores desafios das autoridades sanitárias, o que intensifica as ações e gera maior expectativa em relação ao desempenho do serviço de zoonoses.

O controle de endemias é objeto de discussões permanentes na mídia e nos serviços de saúde, já que as zoonoses estão entre os mais frequentes riscos à população, o que contrasta com a invisibilidade do ACE no seu contexto de trabalho. Apesar de sua importância no enfrentamento das novas e velhas doenças transmitidas pelo Aedes aegypti, os estudos que abordam as condições de vida e saúde destes profissionais são incipientes ${ }^{6}$. As ações em prol da saúde destes trabalhadores têm se resumido à dosagem da atividade da colinesterase sérica e à obrigatoriedade - nem sempre atendida pelos municípios - de a instituição empregadora fornecer equipamentos de proteção individual.

O objetivo desta pesquisa foi identificar e compreender a percepção dos ACE sobre o seu contexto de trabalho, com enfoque na relação entre trabalho e saúde, no âmbito da Secretaria Municipal de Saúde de Belo Horizonte (SMSA/BH).

\section{Métodos}

Este é um estudo transversal, qualitativo, sob o aporte teórico das clínicas do trabalho, com ênfase na psicossociologia do trabalho e na clínica da atividade ${ }^{7}$, teorias que têm como foco a relação entre trabalho e subjetividade e compartilham o interesse central de ser instrumento de transformação dos contextos de trabalho. A clínica da atividade amplia as perspectivas tradicionais de análise, dando ênfase ao poder de agir dos trabalhadores e entendendo o trabalho como fonte permanente de recriação de novas formas de viver ${ }^{8}$.

Para o desenvolvimento do estudo foram utilizadas técnicas de revisão bibliográfica narrativa, utilizando livros e artigos, análise de documentos e grupo focal ${ }^{9}$. A análise documental teve como objeto quatro documentos relativos ao serviço de zoonoses da SMSA/BH, arquivados na Gerência de Gestão do Trabalho e Educação (GGTE) da secretaria.

Os grupos focais foram realizados de outubro a novembro de 2016, em um distrito sanitário de Belo Horizonte escolhido por atender a região com maior número de casos confirmados de dengue na cidade $^{10}$ e ter a maior proporção de ACE afastados do trabalho por motivo de saúde em $2015^{11}$. Os grupos focais exploraram a percepção e os sentimentos dos trabalhadores sobre seu contexto e condições de trabalho, bem como os riscos e as estratégias que utilizam para proteger a saúde física e mental. Os encontros foram planejados com perguntas-chave para abrir a discussão e com roteiro predefinido. 
A pesquisa foi realizada no segundo semestre de 2016. À época, o distrito escolhido para realização dos grupos focais contava com 121 agentes de combate às endemias; 75 atuavam no programa da dengue, distribuídos em 16 unidades de saúde, e 46 trabalhavam na equipe de leishmaniose, distribuídos em dois pontos de apoio. Participaram dos grupos focais ACE de equipes de zoonoses com mais de dez agentes, em efetivo exercício e com vínculo empregatício com a SMSA/BH como empregados públicos ou como contrato administrativo. Esta última modalidade ocorre para atender necessidade excepcional do interesse público, por tempo determinado.

Foram identificadas junto à Gerência de Gestão do Trabalho Regional (GERGETR) seis equipes com mais de dez agentes: quatro que trabalhavam com dengue e duas com leishmaniose. A organização dos ACE em grupos focais designados como G1, G2, G3, G4, G5 e G6 foi feita junto com o distrito, gerentes, encarregados e trabalhadores, por meio de e-mail e telefone. Nem todos os agentes das equipes convidadas participaram, assim, o número de trabalhadores em cada grupo focal variou entre seis e treze agentes, somando o total de 52 profissionais participantes da pesquisa.

Os grupos focais foram realizados nos pontos de apoio de zoonoses de cada equipe, em horário combinado com os profissionais. A duração dos encontros variou de 90 a 120 minutos. Quanto ao perfil dos participantes, 36 (69\%) eram homens. A faixa etária esteve entre 24 e 53 anos, com média de 37 anos, e o grau de escolaridade predominante foi o segundo grau completo. Em média, os trabalhadores tinham dez anos de dedicação à função.

Os dados coletados com os dois procedimentos descritos (análise de documentos e grupo focal) foram interpretados por meio da análise de conteúdo, aqui definida nos termos de Campos ${ }^{12}$, como "um conjunto de técnicas de pesquisa cujo objetivo é a busca do sentido ou dos sentidos de um documento" (p. 611). O método compreendeu: pré-exploração do material e seleção das unidades de análise (temas) orientada pelas questões de pesquisa e categorização apriorística (categorias predefinidas pelos pesquisadores com base na literatura). A categorização e a subcategorização foram realizadas por frequenciamento, ou seja, pela repetição de conteúdos comuns à maioria dos respondentes (Campos, 2004). Categorias não apriorísticas que emergiram da leitura das transcrições também foram registradas.

O projeto foi aprovado pelos comitês de ética em pesquisa da Universidade Federal de Minas Gerais (UFMG) e da Secretaria Municipal de Saúde de Belo Horizonte (SMSA) - CAEE 01140812.1.3001.514.

\section{Resultados e discussão}

Os ACE são profissionais cuja atuação exclusiva no Sistema Único de Saúde foi definida por regulamentação federal através da Lei $n^{0} 11.350 / 2006^{13}$. Sua participação nas equipes a que estão vinculados envolve a realização de atividades coletivas que visam desenvolver práticas educativas associadas à execução de métodos físicos, químicos e biológicos para prevenção e controle das zoonoses prevalentes no município, como dengue, leishmaniose, raiva, controle de roedores e escorpiões, dentre outras ${ }^{14}$. Estas atividades são realizadas majoritariamente por meio de visitas domiciliares no território de abrangência da unidade de saúde.

Segundo Jardim et al. ${ }^{15}$, em Belo Horizonte, a descentralização das atividades do controle de zoonoses começou em 1988, com discussões do processo de municipalização e descentralização das ações de saúde, em consonância com a Constituição recém-promulgada. Em 1990, esse processo se concretizou com o remanejamento dos profissionais do Departamento de Controle de Zoonoses para os distritos sanitários. O município iniciou as atividades de controle de zoonoses a partir da parceria com a Fundação Nacional de Saúde (Funasa). Os funcionários contratados pelo município eram treinados e trabalhavam sob a supervisão dos inspetores da Funasa. Em 1995 e 1996, os serviços de controle de zoonoses foram descentralizados para os centros de saúde, objetivando que os agentes trabalhassem com a população da área de abrangência. No entanto, o processo de descentralização enfrentou muitos desafios, problemas técnicos e políticos, como o corporativismo e a falta de financiamento e preparo do município ${ }^{15}$.

Atualmente, as diretrizes do serviço são dadas pela Gerência de Controle de Zoonoses, no nível central, vinculada à Gerência de Vigilância em Saúde e Informação, na SMSA ${ }^{14}$. Cada distrito sanitário tem uma Gerência de Controle de Zoonoses (segundo nível), com coordenadores que são responsáveis por fazer o elo entre as orientações oriundas do nível central e os encarregados que ficam nas unidades. Cada coordenador é responsável por aproximadamente duas unidades de saúde ou pontos de apoio de leishmaniose e tem como atribuições: planejar ações e supervisionar e acompanhar os resultados do trabalho do ACE em reuniões com os encarregados e gerente de unidade ${ }^{14}$.

O trabalho dos agentes é organizado por agravo: dengue ou leishmaniose. Em Belo Horizonte, o controle de zoonoses iniciou suas atividades visando o Aedes aegypti, vetor transmissor da dengue e zika, e posteriormente incorporou o controle de leishmaniose e outros vetores. Os profissionais que trabalham no 
controle das doenças transmitidas pelo Aedes aegypti são lotados em um ponto de apoio em uma Unidade Básica de Saúde (UBS), onde fazem parte da equipe de atenção primária. Os agentes que atuam no programa de dengue são subordinados ao encarregado e ao coordenador de zoonoses, que é um profissional de nível superior, normalmente biólogo ou veterinário, que fica no distrito sanitário correspondente, e à gerência de zoonoses distrital. Além disso, é subordinado administrativamente ao gerente da unidade.

Os agentes que ficam no ponto de apoio de leishmaniose visceral são subordinados ao encarregado, ao coordenador e ao gerente de zoonoses distrital. Para um grupo de oito a dez agentes, haverá um ACE II, ou um encarregado, que é responsável pela equipe. Este, por sua vez, é coordenado por um técnico superior de saúde ou um coordenador de área, que assume mais áreas de abrangência ${ }^{14}$.

De acordo com as diretrizes de organização da assistência da SMSA, os ACE são parte integrante da atenção básica, e portanto uma das equipes que compõem os centros de saúde do município ${ }^{14}$. Mas os relatos dos profissionais parecem apontar para outra realidade:

\begin{abstract}
Na verdade ainda não somos parte da saúde. A zoonoses é parte da saúde burocraticamente, para nós é uma forçação de barra, porque tem a dengue e tem que ter a gente, mas não tem aquela ligação com o posto de saúde como se fosse uma coisa só, nós somos vistos como uma coisa à parte. (G5)
\end{abstract}

O pessoal lá de dentro não reconhece a gente como parte da equipe lá de dentro, parece que cortou um pedaço da parede e não fazemos parte. Somos rejeitados pelo centro de saúde. (G2)

Existe profissional que olha a zoonoses como intruso. (G6)

Estudo recente de Fraga e Monteiro ${ }^{16}$, realizado na SMSA/BH com uma equipe de zoonoses, corroborou essa percepção de não pertencimento, marginalização e discriminação relatada pelos agentes. As autoras apontam que, embora a instituição se esforce para incorporar estes profissionais à atenção básica, essa posição não está consolidada ${ }^{16}$.

Segundo Enriquez ${ }^{17}$, o indivíduo não expressa apenas seu desejo próprio num grupo, ele quer igualmente ser reconhecido como um de seus membros. A questão do reconhecimento sempre foi abordada no estudo das relações humanas, remetendo ao relacionamento consigo mesmo e com o outro, tratado na filosofia, na psicologia social e nas clínicas do trabalho com enfoques diferentes. Honneth ${ }^{18}$ afirma que vários sofrimentos e angústias contemporâneas estão associadas a modalidades de negação de reconhecimento e desrespeito.

Conforme alerta Lhuilier ${ }^{19}$, é importante considerar as dimensões da divisão técnica, social, moral e psicológica do trabalho que atravessam a questão do reconhecimento. Segundo a autora, "existe inclusive uma escala de desejabilidade moral e psicológica das profissões e das atividades. Ela diferencia profissões prestigiadas de outras desconhecidas ou estigmatizadas" (p. 16). Essa perspectiva faz pensar que a falta de reconhecimento destacada pelos ACE tem origens mais complexas e remete à "fabricação baseada em processos de delegação e no fato de serem jogadas na invisibilidade as atividades desinvestidas e desvalorizadas" (p. 16) ${ }^{19}$. Esse estigma sobre determinado trabalho contamina também a pessoa que o exerce, influenciando sua própria autoimagem ${ }^{19}$.

Os relatos dos ACE sugerem que a exclusão e a desigualdade de tratamento fazem parte do seu contexto de trabalho, sendo percebidas como os aspectos mais difíceis de lidar e que produzem maior sofrimento.

\begin{abstract}
Quando você vai ao distrito e não é bem recebido... Aqui tem muito "preconceito de classe", como eles dizem. No nosso nível de classe a gente não é bem recebido. Aqui a gente tem médico, enfermeiro, cada um tem um nível de classe. Para mim, todos deveriam ser iguais, porque trabalhador é trabalhador. Eu quero ser bem tratado, respeitado. (G1)
\end{abstract}

Barros e Santos ${ }^{20}$ apresentaram resultados semelhantes em pesquisa realizada com serventes de obras. Segundo os autores, "as profissões avaliadas como mais ou menos nobres estão situadas em uma hierarquia de reconhecimento e valorização social” (p. 247), e os últimos patamares dessa hierarquia são as profissões desvalorizadas e sem qualificação.

A invisibilidade - ponto que causa indignação no grupo de ACE - remete ao desaparecimento simbólico de indivíduos com profissões que não exigem qualificação escolar ou técnica ${ }^{21}$ :

Aqui tem muito isso, eles não enxergam a gente, a ponto de a gente chegar na cozinha e dar bom dia e nem te verem, nem respondem [...] Isso também atrapalha a gente, é muito chato a pessoa nem dar bom dia, principalmente se tiver médico e enfermeiro. (G1)

Esse tipo de sentimento foi identificado por Costa $^{21} \mathrm{em}$ seu estudo com os garis. Para o autor, a invisibilidade tem estreita relação com a segregação social, isto é, quanto maior a distância social, maior a probabilidade de o sujeito ficar invisível ao outro:

A cegueira de gente que não vê gente é traumática, causa angústia. A cegueira de gente que não vê gente dispara humilhação. E, mais precisamente cegueira política: cegueira de uma classe quanto à outra 
classe, a classe a serviço da primeira em condições de subordinação. (p. 15)

Costa $^{21}$ aponta que a subjetividade de um homem é demandada pela subjetividade de outro homem, portanto o reconhecimento do outro enquanto semelhante constitui um "fenômeno psicossocial" (p. 15). Assim, o autor entende que a invisibilidade pública é expressão de dois fenômenos que assumem caráter crônico nas sociedades capitalistas: humilhação social e reificação. Reificação é a transformação de uma pessoa em uma coisa. $\mathrm{O}$ conceito associa-se à forma de relação social característica do modo de produção capitalista, em que a subjetividade humana é submetida e identificada aos produtos e objetos produzidos e comercializados, implicando a coisificação das relações. A invisibilidade pública é resultado histórico, de longa duração, que o capitalismo perpetua e naturaliza. Nesse cenário, a percepção do outro é diminuída, especialmente a percepção de alguém vinculado a trabalhos considerados desqualificados ${ }^{21}$.

A invisibilidade pública - construção social e psíquica - tem a força de ressecar expressões corporais e simbólicas dos humanos então apagados. Pode abafar a voz e baixar o olhar. Pode endurecer o corpo. Pode emudecer os sentimentos e fazer fraquejar a memória. Faz esmorecer - em todos estes níveis - o poder de aparição de alguém. (p. 15) 21

Em que pesem as exigências técnicas e de segurança do processo de trabalho, que demandam segregação de inseticidas e equipamentos utilizados pelos ACE, a precariedade e o desconforto dos pontos de apoio das equipes de zoonose (que na maioria das vezes funcionam em espaço improvisado, pequeno e escondido), somados à indiferença dos outros trabalhadores a esta situação, reforçam o sentimento de invisibilidade. Os agentes relatam esse fato nos grupos:

Um dia você pode tirar e ir em todos os postos de saúde e vai ver a sala de zoonoses; é sempre a escória, debaixo de uma escada, num beco, escondido. (G4)

Nós somos o lixão. (G1)

\section{Percepção dos problemas de saúde e riscos no trabalho}

Os principais riscos à saúde reconhecidos pelos ACE são a falta de condições de trabalho adequadas, a violência e os riscos psicossociais.

A análise do relatório da Gerência de Saúde do Servidor e Perícia Médica (GSPM) e da Gerência de Engenharia e Segurança no Trabalho (GEESEG) ${ }^{22}$ demonstra que as condições precárias de trabalho dos agentes de zoonoses são um problema já identificado há muito tempo. Segundo o relatório, os dados obtidos nas inspeções ratificam diversos levantamentos técnicos realizados pela GSPM/GEESEG desde o ano de 1999. O documento conclui que "as condições de trabalho dos funcionários de zoonoses ainda deixam muito a desejar no que se refere à saúde e segurança" (p. 3). Os principais problemas detectados nos pontos de apoio se referem à área física (paredes com infiltração e ausência de lugares adequados para refeição, para armazenar os produtos químicos e para lavar os equipamentos utilizados, bem como de instalações sanitárias separadas por sexo).

Após seis anos, os relatos dos ACE corroboram os dados apresentados no relatório ${ }^{22}$. Na percepção dos profissionais que participaram da pesquisa, as condições de trabalho na Prefeitura de Belo Horizonte não são adequadas para realização de suas atividades.

$O P A$ [ponto de apoio] não tem condições de trabalho, tem um banheiro masculino para 40 homens usarem. Tinha que ter vestiário. A gente trabalha com produto químico e teria que chegar aqui e tomar banho, tem por obrigação tomar banho, mas tem que esperar 40 homens para tomar banho. (G4)

A falta de equipamento de proteção individual (EPI) também é um dos problemas apresentados no relatório da perícia médica e que aparece nos relatos dos trabalhadores. Na percepção dos ACE, a falta de equipamentos de proteção e insumos é um problema que impacta significativamente suas atividades. Além disso, os profissionais ressaltam que os equipamentos não são de boa qualidade:

A gente quer fazer o sistema funcionar, mas trabalha sem condições. Já teve época que o protetor veio vencido e a gente não deixava de ir para a rua porque não tinha protetor solar. Até vir outro a gente trabalhava no sol sem protetor. (G2)

Os agentes expressam certo conflito em relação ao contexto de trabalho. Como reclamar da bota diante da ausência de outras coisas na unidade?

Vai faltando tudo aqui, tirou porteiro, posso ajudar, falta remédio e eu vou brigar por causa de uma bota, entende? É complicado isso. (G2)

Os relatos sugerem que os trabalhadores não têm convicção de que o EPI é um direito, e que é legitimo reivindicá-lo. Eles refletem também acerca de suas próprias atitudes diante do campo, as quais, muitas vezes, podem trazer risco à saúde:

Se você não fizer, você é negligente, mas, se fizer, corre risco. A gente não sabe o que fazer, entende? Ninguém vem aqui ver as nossas condições de trabalho. (G2)

O SUS é resultado da luta da base da sociedade que defende a democratização da saúde e a reestruturação do sistema de serviços, composta por estudantes, pesquisadores, universidades, profissionais 
de saúde, sindicatos, entidades comunitárias e sociedades científicas ${ }^{23}$. Mas, apesar da mobilização dos diferentes segmentos envolvidos na criação e na idealização desse sistema, criar condições e estrutura para seu funcionamento tem sido difícil, principalmente em face das desigualdades socioeconômicas no Brasil e da influência neoliberal. Uma das realidades no trabalho dos profissionais da saúde é a necessidade frequente de ter que fazer escolhas na falta de meios materiais para gerir o cotidiano de trabalho ${ }^{7}$.

O relatório final da VIII Conferência Nacional de Saúde ${ }^{24}$ considera como premissa que o exercício do direito à saúde implica garantir "condições dignas, com amplo conhecimento e controle dos trabalhadores sobre o processo e o ambiente de trabalho" (p. 5). Porém, apesar de toda a história do SUS, reconhecida pelas lutas e vitórias em prol de melhores formas de vida - "pelo empoderamento dos atores sociais, inclusão e emancipação dos sujeitos e dos coletivos" (p. 120) ${ }^{25}$-, as condições de trabalho permanecem precárias.

Os riscos psicossociais também aparecem nos relatos dos ACE, relacionados a um descompasso entre a oferta de recursos e as exigências do cumprimento das tarefas. Na percepção dos ACE, a produtividade está, na maioria das vezes, descolada do serviço bem feito, da qualidade e do resultado: "A instituição quer número, querem mostrar para a sociedade" (G4).

Rosseti e Araújo ${ }^{26}$ entendem que os riscos psicossociais incluem "aspectos relativos às condições e à organização do trabalho, aos modelos deletérios de gestão, bem como aos contextos sociais e ambientais que causam danos de tipo físico, social ou psicológico" (p. 118). Os autores observam que esses riscos podem estar na origem do absenteísmo, da alta rotatividade e de vários adoecimentos no trabalho, como estresse, doenças osteomusculares e abuso de drogas.

Segundo Oliveira ${ }^{6}$, a organização das ações de controle das endemias apresenta forte tendência à gestão verticalizada, com estabelecimento de metas objetivas e quantificáveis, priorizando estratégias instrumentalizadas nos mecanismos de controle e supervisão do trabalho do ACE para intensificação das ações. Essa forma de organização remete ao modelo adotado no controle de endemias pelo Departamento Nacional de Endemias Rurais (DNERu), entre as décadas de 1950 e 1970, e pela Superintendência de Campanhas de Saúde Pública (Sucam), entre as décadas de 1970 e 1990, influenciado pelas experiências dos serviços de saúde dos exércitos coloniais e do modelo biomédico para explicação das doenças ${ }^{6}$.

A exigência de produtividade descolada da preocupação com a qualidade e a percepção de pouco poder para resolver os problemas identificados no campo foram temas de discussão em todos os grupos.
Os relatos dos agentes sugerem desgaste no contexto de trabalho diante do esforço empenhado e os resultados obtidos no controle das endemias: "A gente cientifica, cientifica, mas nada acontece, o trabalho perde a credibilidade na comunidade. $E$ muito difícil isso, sabe?" (G2). Como afirma $\mathrm{Clot}^{8}$ : "excesso de atividade e sentimento de insignificância formam, nesse caso, uma mistura explosiva" (p. 11).

Outro aspecto apontado pelos trabalhadores é a falta de participação nas decisões sobre o processo de trabalho, mesmo quando essas se relacionam aos seus territórios. Os agentes ressaltam que isso gera sentimento de insatisfação:

Penso eu que o nosso problema aqui não é o trabalho, não é que é difícil, que é chato, mas o problema é que não se discute processo de trabalho aqui, eles trazem as coisas prontas. (G1)

A centralização das decisões acerca da organização do processo de trabalho nas equipes de zoonoses também foi constatada no estudo de Fraga ${ }^{16}$. A autora observa que há tentativas do nível central do serviço de zoonoses de incluir os ACE na elaboração de políticas, no entanto,

\begin{abstract}
os agentes são convidados a participar para legitimar processos e decisões tomadas por outros profissionais e para solucionarem problemas que não dão conta. Durante a reunião entre coordenadores e agentes, observou-se que os ACEs foram convidados a se manifestar mais como prova do compromisso com a democracia do que com o real interesse de valorização do saber daqueles profissionais. Tal situação tende a gerar resistência e falta de motivação, resultando em um agir descompromissado e descolado da missão institucional. (p. 10) ${ }^{16}$
\end{abstract}

A fala de um trabalhador resume a forma de organização percebida na instituição:

Você já viu cavalo de charrete? A gente só pode olhar assim [gesto com a mão, de estreitamento]. (G1)

O engessamento exigido para o trabalho e a dicotomia entre quem planeja e quem executa pode ter efeitos na atividade desses profissionais. Segundo $\mathrm{Campos}^{27}$, a imprevisibilidade dos casos que se apresentam ao profissional de saúde exige criatividade, iniciativa e improvisação para resultar numa resolução eficaz. Sendo assim, a autonomia é fundamental para a atuação do profissional.

Enriquez ${ }^{17}$ destaca que o pensamento inventivo é desejado e temido pelas organizações. Desejado no sentido de produção, temido porque pode ameaçar a ordem definida. Nesse sentido, o autor afirma que há um temor em relação ao pensamento em seus aspectos inventivos e criativos. 
Outro trabalhador relata: "Aqui eles querem uma comissão local [com] corpos dóceis e trabalhadores [com] corpos dóceis, entende?" (G1). Conforme afirma Foucault ${ }^{28}$, "é dócil o corpo que pode ser submetido, que pode ser utilizado, que pode ser transformado e aperfeiçoado" (p.163).

Outro risco apontado pelos ACE é a violência, percebida como ameaça à saúde e à integridade física e mental. A violência no trabalho é um importante problema de saúde pública, que tem impacto na dignidade e na qualidade de vida do trabalhador. Mesmo as atividades que, a priori, não são consideradas sujeitas à violência e à exclusão, convivem atualmente com tais fenômenos ${ }^{29,30}$. A realidade é descrita pelos ACE em todos os grupos:

Uma vez, numa casa, uma fila começou a se formar, porque a boca ia abrir. O cara perguntou: "Vocês querem peixe?". A gente respondeu que a gente estava trabalhando, então ele mandou a gente vazar, e ele estava com um facão [...]. Aí a agente foi falar com ele e ele bateu nela com o facão. (G5)

Tem os locais de boca de fumo, a gente está exposta e a gente nem sabe. Na minha área tem muito morador de rua, usuários de drogas, e a gente que é mulher não sabe o que pode acontecer. (G1)

Os ACE convivem com a violência no seu contexto de trabalho de forma muito próxima e, apesar dela, acabam desenvolvendo meios para realizar sua atividade:

Na vila tem o tráfico de drogas e a gente tem que ter cuidado, você está passando e vê o que está acontecendo, mas com o tempo você acostuma. (G6)

Além da violência urbana e das condições precárias de trabalho, os agentes percebem também como risco o assédio sexual, principalmente para as mulheres, acidentes com cachorro, quedas, exposição ao sol, contaminação por doenças infecciosas e contato com veneno (produtos químicos).

O Relatório de Bonificação por Cumprimento de Metas, Resultados e Indicadores ${ }^{11}$ aponta que as causas mais frequentes dos afastamentos do trabalho por licença médica por até 15 dias são as doenças do sistema osteomuscular (20\%), seguidas pelas lesões, envenenamentos e consequências de causas externas (15\%) e transtornos mentais e comportamentais (14\%). Há também registros de afastamentos por doenças do aparelho respiratório (7\%) e circulatório (8\%), doenças infecciosas e parasitárias/aparelho digestivo (7\%) e neoplasia (2\%). Existem ainda registros de 10\% de casos codificados na Classificação Internacional de Doenças como fatores que influenciam o estado de saúde e contato com serviço de saúde (categorias fornecidas para ocasiões em que outras circunstâncias que não uma doença, um traumatismo ou outra causa externa justificam a ausência ao trabalho). Aparecem outras causas, como doença dos nervos, de pele, do sangue, do aparelho urinário, dos olhos, nutricionais e de ouvido que, juntas, correspondem a $17 \%$ do total de casos de afastamento no referido período.

As queixas dos ACE no grupo focal coincidem com as proporções apresentadas nesse relatório: "Dores na perna, nas costas, é assim direto, já me acostumei” (G2); "Coluna dói e tem dia que você não aguenta" (G1). As doenças osteomusculares identificadas são fraturas, entorses, dores lombares, dores no joelho e dedos. As causas de adoecimento dos agentes são semelhantes às encontradas em outros estudos, como o realizado com agentes do Ceará em $2015^{31}$.

Um dos problemas que mais atinge trabalhadores e vem aumentando consideravelmente são as lesões por esforços repetitivos ou distúrbios osteomusculares relacionados ao trabalho. Tratam-se de doenças decorrentes da utilização excessiva do sistema musculoesquelético e da falta de tempo para recuperação, não existindo causa única e determinada. São vários os fatores que podem estar relacionados à sua gênese: repetição de movimentos, manutenção de posturas inadequadas por tempo prolongado, esforço físico, invariabilidade de tarefas, pressão mecânica sobre determinadas partes do corpo, trabalho estático, frio, fatores organizacionais e psicossociais ${ }^{31,32}$.

Aparecem também relatos de adoecimento por intoxicação por veneno (agrotóxico). A categoria profissional é a mais suscetível aos efeitos dos inseticidas nas campanhas antivetoriais, pois a exposição se dá desde o preparo do produto até a aplicação nas áreas intra ou peridomiciliares, onde os ACE absorvem os produtos químicos pelas vias dérmica e aérea. Fatores como falta de EPI ou desconhecimento da forma correta de manipulação de cada produto aumentam os riscos de intoxicação ${ }^{3}$. Os agentes reconhecem o risco e o impacto para a saúde:

Eu mesmo fiquei afastado quatro meses, no meu caso, foi intoxicação por produto químico. Na época eu tinha tenossinovite, estava com as mãos inchadas. (G1)

A questão da remuneração e qualidade de vida também foi muito discutida nos grupos focais. A percepção predominante é de que a baixa remuneração tem impacto na saúde e na qualidade de vida, já que impede os agentes de desfrutar de lazer com a família, viajar nas férias e se alimentar bem. Além disso, como a remuneração é insuficiente, alguns ACE trabalham em outros lugares à noite ou nos fins de semana - realidade também apontada no estudo de Fraga ${ }^{16}$, em que $69 \%$ dos agentes afirmaram ter outras fontes de renda

Apesar das adversidades, os profissionais reconhecem o papel social de sua atividade, criam alternativas para realizá-la e afirmam que o trabalho é 
bem feito. Alguns expressam certo orgulho da profissão, principalmente quando recebem feedback positivo do munícipe. Eles usam a criatividade e recursos próprios para viabilizar o trabalho e demonstram satisfação ao se verem como protagonistas. A satisfação é expressada nestes relatos:

E também os meninos tentam ajudar, tampam a caixa d'água, eles mesmos fazem as tampas, ou usam lona. A gente faz com nossos recursos, a prefeitura nem sabe disso, não é nossa atribuição, a gente improvisa ou a gente pede em outros lugares, a gerente ajuda também. [...] Chega o SAC [Serviço de Atendimento ao Cliente] para roedor e não tem veneno, e você tem de usar a criatividade, ensina a fazer uma barreira física, orienta a fazer uma limpeza. (G6)

Como afirmam Rosseti e Araújo ${ }^{26}$, “a resistência, quando criativa, abre caminho também para a possibilidade de prazer, para o sentimento de autorrealização no trabalho” (p. 119).

A percepção do trabalho bem feito e a união entre os membros da equipe também aparecem como um fator de proteção à saúde:

Tudo que acontece aqui a gente se apoia; a gente se ajuda. Somos um para o outro, isso alivia. (G5)

Conforme Chanlat ${ }^{33}$, "o lugar de trabalho é um lugar de socialização e de encontros” (p. 131). É espaço dividido e imposto, que fixa de algum modo a identidade pessoal e social e fornece referências para se transformar, interagir, produzir, criar laços afetivos e se fortalecer.

\section{Considerações finais}

A pesquisa evidenciou que o serviço de zoonoses é percebido pelos profissionais como não integrado à saúde, e essa é uma das causas da precariedade das condições de trabalho, do sentimento de invisibilidade e da marginalização simbólica e concreta relatada pelos agentes.

Os resultados são semelhantes aos de outras pesquisas com categorias menos valorizadas, como garis, agentes comunitários de saúde e auxiliares de enfermagem. Para além de identificar a situação de trabalho do ACE no município de Belo Horizonte, a pesquisa aponta para a invisibilidade e o sofrimento vivenciados por trabalhadores de categorias pouco prestigiadas socialmente.

Há que se discutir a contradição entre a idealização de um SUS essencialmente inclusivo e solidário e práticas de exclusão e marginalização em seus serviços. A organização reproduz a lógica que predomina na sociedade, valores, comportamentos e formas de relacionamento, e por isso é importante que perceba suas contradições internas e se indague sobre sua missão institucional e suas práticas.

A lógica do modelo socioeconômico capitalista permeia os serviços de saúde, materializada nas condições precárias de trabalho - ou seja, a obrigação de fazer mais com menos recursos -, na valorização da produtividade em detrimento da qualidade, na gestão verticalizada e na falta de autonomia do trabalhador.

Diante deste cenário, não é possível concluir, mas iniciar, incitando nos gestores reflexões acerca do fazer dos agentes de combate às endemias. É preciso desenvolver o poder de agir desses profissionais, sua autonomia e criatividade. Esse pode ser o caminho para pensar a relação entre trabalho e saúde nos serviços de zoonoses, assim como atingir os objetivos esperados na prevenção e controle dessas doenças.

\section{Contribuições de autoria}

Matos GCR, Silva JM e Silveira AM, contribuíram na concepção e planejamento da pesquisa; na coleta, análise e interpretação dos dados; e na elaboração e aprovação da versão final do manuscrito. Todas as autoras assumem responsabilidade pública pelo conteúdo do trabalho.

\section{Referências}

1. Clot Y. Prefácio à edição brasileira. In: Lima MEA, organizadores. Escritos de Louis Le Guillant: da ergoterapia à psicopatologia do trabalho. Petrópolis: Vozes; 2006. p.13-22.

2. Enriquez E. O trabalho, essência do homem? O que é o trabalho? Cad Psicol Soc Trab. 2014;17(Spec No 1):163-176.
3. Organização Internacional do Trabalho. A prevenção das doenças profissionais. Genebra: OIT; 2013.

4. Mehry EE. Saúde: a cartografia do trabalho vivo. $3^{\mathrm{a}}$ ed. São Paulo: Hucitec; 2002.

5. Nobre LCC et al., organizadores. Orientações técnicas para proteção da saúde dos agentes de saúde. Salvador: Cesat/Divisa/Divep/Dab/Sais/Ciave; 2012. 
6. Oliveira MVASC. A educação popular em saúde e a prática dos agentes de controle das endemias de Camaragibe: uma ciranda que acaba de começar [dissertação]. João Pessoa: Universidade Federal da Paraíba; 2002.

7. Bendassoli PF, Soboll LA, organizadores. Clínicas do trabalho: novas perspectivas para compreensão do trabalho na atualidade. São Paulo: Atlas; 2011.

8. Clot Y. Trabalho e poder de agir. Belo Horizonte: Fabrefactum; 2010

9. Flick U. Introdução à pesquisa qualitativa. Porto Alegre: Artmed, 2009.

10. Pimenta FG Jr, Guerra MJ, Carvalho MJM, Monteiro TAMC. Relatório de gestão de 2015 [Internet]. Belo Horizonte: Secretária Municipal de Saúde; 2018 [citado em 15 jun 2018]. Disponível em: https:// prefeitura.pbh.gov.br/sites/default/files/estruturade-governo/saude/2018/documentos/planejamento/ RAG-2015.pdf

11. Belo Horizonte. Secretaria Municipal de Saúde. Relatório de bonificação por cumprimento de metas, resultados e indicadores, 2015. Belo Horizonte: Secretaria Municipal de Saúde; 2015.

12. Campos CJG. Método de análise de conteúdo: ferramenta para a análise de dados qualitativos no campo da saúde. Rev Bras Enferm. 2004;57(5):611-614.

13. Brasil. Lei $n^{0} 11.350$, de 5 de outubro de 2006 . Regulamenta o $\S 5^{\circ}$ do art. 198 da Constituição, dispõe sobre o aproveitamento de pessoal amparado pelo parágrafo único do art. $2^{\circ}$ da Emenda Constitucional $\mathrm{n}^{0} 51$, de 14 de fevereiro de 2006, e dá outras providências. Diário Oficial da União. 5 out 2006.

14. Belo Horizonte. Secretaria Municipal de Saúde. Manual técnico: padronização das ações para controle vetorial da dengue desenvolvidas no município de Belo Horizonte [Internet]. Belo Horizonte: SMSA, 2009 [citado em 6 maio 2020]. Disponível em: https://prefeitura.pbh.gov.br/sites/ default/files/estrutura-de-governo/saude/2018/ publicacaoes-da-vigilancia-em-saude/manual dengue_padronizacao_acoes_controle_vetorial_ dengue_BH.pdf

15. Jardim CCG, Oliveira CL, Cunha MCM, Brandão ST. A descentralização do controle de endemias: uma aposta do município de Belo Horizonte. In: Campos CR, Malta DC, Reis AT, Santos AF, Mehry E. Sistema Único de Saúde de Belo Horizonte: reescrevendo o público. São Paulo: Xamã, 1998. p. 365-380.

16. Fraga LS, Monteiro S. A gente é um passador de informação: práticas educativas de agentes de combate a endemias no Serviço de Controle de Zoonoses em Belo Horizonte. Saude Soc. 2014;23(3):993-1006.

17. Enriquez E. A organização em análise. Petrópolis: Vozes; 1997.
18. Honnneth, A. Luta por reconhecimento. São Paulo: Editora 34; 2003.

19. Lhuilier D. Introdução à psicossociologia do trabalho. Cad. Psicol Soc Trab. 2014; 17 Spec No 1:5-19.

20. Barros VA, Santos PHF. Atividades marginalizadas: o servente da construção civil. In: Araújo JNG, Ferreira, MC, Almeida CP, organizadores. Trabalho e saúde: cenários, impasse e alternativas no contexto brasileiro. São Paulo: Opção; 2015. p. 247-268.

21. Costa FB. Homens invisíveis: relatos de uma humilhação social. São Paulo: Globo; 2004.

22. Belo Horizonte. Secretaria Municipal de Saúde. Relatório de inspeção dos pontos de apoio do serviço de zoonoses. Belo Horizonte: Gestão do Trabalho e Educação em Saúde, 2011.

23. Conselho Nacional de Secretários de Saúde. Conass 25 anos. Brasília: Conass; 2007.

24. Brasil. Ministério da Saúde. $8^{\mathrm{a}}$ Conferência Nacional de Saúde: relatório final. Brasília: Ministério da Saúde; 1986.

25. Araújo JN, Rosseti CC. Trabalho no SUS e a saúde no trabalho: possibilidade ou paradoxo? In: Araújo JNG, Ferreira MC, Almeida CP, organizadores. Trabalho e saúde: cenários, impasses e alternativas no contexto brasileiro. São Paulo: Opção; 2015. p. 119-138.

26. Rosseti CC, Araújo JNG. Resistência e criatividade: trabalho dos médicos do Programa Saúde da Família. Trabalho (En)Cena. 2016;1(1):117-131.

27. Campos GWS. Subjetividade e administração de pessoal: considerações sobre modos de gerenciar o trabalho em equipes de saúde. In: Mehry E, Onokco R, organizadores. Agir em saúde: um desafio para o público. $3^{\mathrm{a}}$ ed. São Paulo: Hucitec; 2007. p.229-266.

28. Foucault M. Vigiar e punir: nascimento da prisão. Petrópolis: Vozes; 1987.

29. Campos AS. A violência como objeto para a saúde do trabalhador: agressões contra trabalhadores das unidades básicas de saúde do distrito sanitário norte de Belo Horizonte (dissertação). Belo Horizonte: Universidade Federal de Minas Gerais; 2004.

30. Oliveira RP. Nunes MO. Violência relacionada ao trabalho: uma proposta conceitual. Saude Soc. 2008;17(4):22-34.

31. Ferreira AR Jr, Torres ARA, Silva CMA. Condições laborais dos agentes de combate a endemias e seus efeitos na saúde. Essentia. 2015;16:77-95.

32. Brasil. Ministério da Saúde. Política Nacional de Atenção Básica. Brasília: Ministério da Saúde; 2012.

33. Chanlat JF. O desafio social da gestão: a contribuição das ciências sociais. In: Bendassolli PF, Soboll LAP, organizadores. Clínicas do trabalho: novas perspectivas para compreensão do trabalho na atualidade. São Paulo: Atlas; 2011. 